\title{
Solubility and Seeded Metastable Zone width of functional sugar L-arabinose
}

\author{
Biao $\mathrm{HU}^{1 \star}$, Kai HUANG ${ }^{1}$, Xinlin $\mathrm{ZHANG}^{1}$, Pingjun $\mathrm{ZHANG}^{1}$, Shujuan $\mathrm{YU}^{1}$
}

\begin{abstract}
L-arabinose is widely used in food, medicine, chemistry, and biology fields; however, solubility and seeded metastable zone width (MSZW) of L-arabinose have not been reported in the literature. In this paper, solubility and MSZW of L-arabinose in aqueous solution were determined. Solubility of L-arabinose was measured in the range of $20-68^{\circ} \mathrm{C}$ by a conventional equilibrium solubility method and quantitation was determined using the ion chromatography technique. Seeded MSZW was determined in the range of $51-73 \%$ by the calorimetric method. The effect of two salts (potassium chloride and calcium chloride) on the solubility and MSZW of L-arabinose were also evaluated. Results showed that both potassium chloride and calcium chloride increased the solubility of L-arabinose, and this increase was intensified with temperature rise. The MSZW of L-arabinose was not constant but a spread. Potassium chloride increased the MSZW of L-arabinose. However, the effect of calcium chloride on MSZW of L-arabinose was concentration dependent. Conclusion: the L-arabinose solubility increased with the increase in temperature, and both potassium chloride and calcium chloride increased the solubility of $\mathrm{L}$-arabinose in aqueous solution. The seeded MSZW of L-arabinose is not a constant; it increases in the presence of potassium chloride and varies with the change in calcium chloride concentration.
\end{abstract}

Keywords: sucrase; ion chromatography; potassium chloride; calcium chloride.

\section{Introduction}

L-arabinose is a new functional low-caloric sugar with selective intestinal sucrase inhibition effect (Seri et al., 1996; Shibanuma et al., 2011; Krog-Mikkelsen et al., 2011; Liu et al., 2013). The taste of L-arabinose is quite similar to that of sucrose, with approximately $50 \%$ the sweetness of sucrose. It can be used as a functional additive for improving obesity and maintaining good health (Yoon et al., 2003; Po et al., 2011; Fu-Yu et al., 2010). $\mathrm{L}$-arabinose is the critical agent in the synthesis of antiviral drug clevudine (Choung et al., 2012) and telbivudine (Jia et al., 2014; Li et al., 2014), which are potent anti-hepatitis B (HBV) agents. It also has great usage in tumor therapy (Loessner et al., 2007; Jeong et al., 2014; Kaluzhny et al., 2009) and chemistry (Yamauchi \& Kinoshita, 2001; EL-Farargy \& Ghonium, 2008) and biology fields (Becker \& Boles, 2003; Jeon et al., 2010). Although it has been known for a long time, the solubility and metastable zone width of $\mathrm{L}$-arabinose in aqueous solution have not been reported before.

Solubility is a thermodynamic property of a material, and it depends on its chemical composition, nature of the solvent(s), and temperature. The extent of the supersaturation or supercooling is referred to the metastable zone width (MSZW). The equilibrium and kinetic methods have usually been used for solubility determination (Black et al., 2013; Andrade et al., 2003; Elder \& Holm, 2013; Três et al., 2007; Zhang et al., 2012), while methods such as turbidity monitoring (Zhang et al., 2012; Rabesiaka et al., 2011), Focused Beam Reflectance Measurement (FBRM), (Barrett \& Glennon, 2002; Sun et al.,2010), and electric conductivity method (Wu et al., 2012) have been used for MSZW determination.
Crystallization is the phase transition of matter from the state of a supercooled or supersaturated mother medium to a crystalline state with lower energy. Excess energy dissipates in the form of the latent heat during the transformation (Salomatov, 1966; Mikhalev et al., 1985). The dissipation of the latent heat increases the temperature of the solution, which can be immediately recorded by a real-time recording thermometer (Shiroishi et al., 1999). Thus, the calorimetric method can be an alternative method for MSZW detection.

In the present study, solubility of L-arabinose in aqueous solution was measured in the temperature range of $20^{\circ} \mathrm{C}$ to $68^{\circ} \mathrm{C}$, and the MSZW was detected by the calorimetric method from $51-73 \%$. The effect of two salts on the solubility and seeded metastable zone width of $\mathrm{L}$-arabinose were also evaluated. The findings obtained can be useful in the industrial production of L-arabinose.

\section{Material and methods}

\subsection{Materials}

L-arabinose (99.7\% purity) was purchased from Shandong Futaste Co. Ltd. The purity of the L-arabinose was analyzed by ion chromatograph (Dionex, ICS5000). The measurement was performed using carbopac@PA1 column with electrochemical detection under the following conditions: $100 \mathrm{mM} \mathrm{NaOH}$, $1.0 \mathrm{~mL} / \mathrm{min}$; injection volume: $20 \mu \mathrm{L}$, and temperature: $30^{\circ} \mathrm{C}$. The chromatogram indicates presence only of a sharp peak at 2.9 minutes. X-ray diffraction (XRD) analyses confirmed that the purchased needle-like material is really the L-arabinose 
crystalline. The XRD spectrum (Figure 1) was obtained on a Bruker D8 Advance X-ray diffractometer (Bruker, Germany) using conventional $\mathrm{Cu}$ Ka radiation $(\lambda=1.54 \AA)$ at $33 \mathrm{kV}, 45 \mathrm{~mA}$. Data were collected between 2 -theta degrees values of $8.0^{\circ}$ and $60.0^{\circ}$ with a step width of $0.02^{\circ}$. Impurities (Potassium chloride and Calcium chloride of analytical grade) were used without further purification. Deionized water was used in all experiments.

\subsection{Experimental setup}

\section{Standard curve of L-arabinose}

A standard curve of L-arabinose measured by ion chromatograph (Dionex, ICS5000) is shown in Figure 2. The measurement condition was consistent with that of L-arabinose purity determination. The relationship between the peak area and L-arabinose concentration was expressed by Equation 1.

$A=8.0787 \times 10^{3} \times C\left(R^{2}=0.9964\right)$

Where $A$ is the peak area and $C$ is the concentration. The peak area and L- arabinose concentration showed an excellent linear relationship from $15.625 \mathrm{ppm}$ to $700 \mathrm{ppm}$, indicating that ion chromatography is an effective analytic method for L-arabinose.

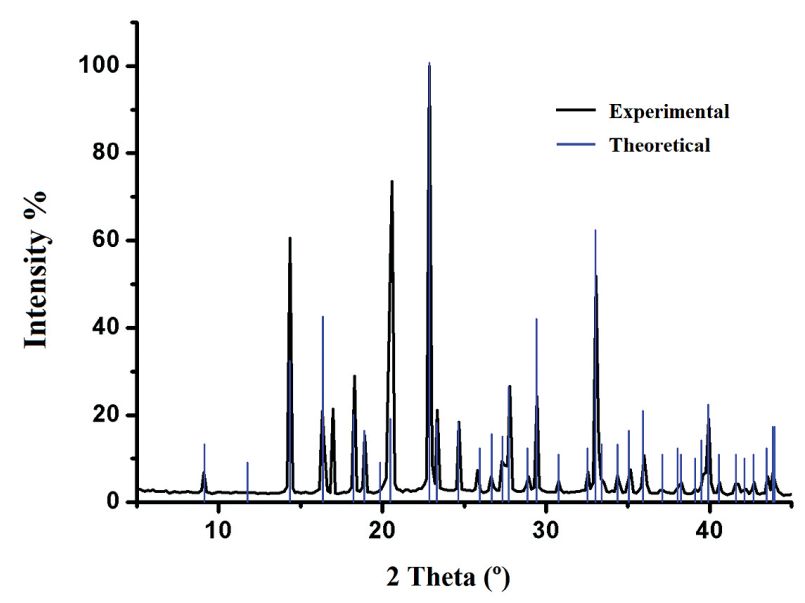

Figure 1. XRD of commercial L-arabinose.

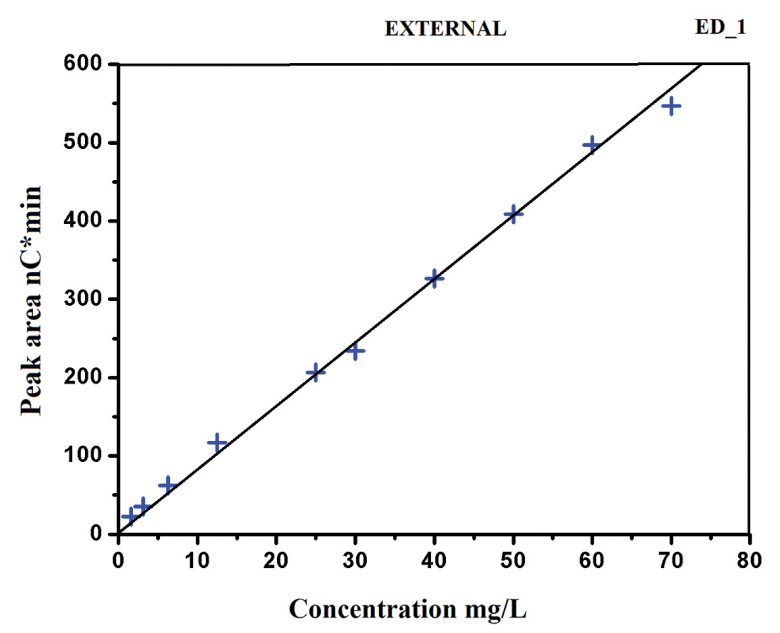

Figure 2. Standard curve of L-arabinose by Ion Chromatography.

\section{Solubility of L-arabinose in pure water system}

An excess of L-arabinose was added to $20 \mathrm{~mL}$ water and kept in a water bath with a magnetic stirrer; it was stirred once every hour for $8 \mathrm{~h}$ and kept still overnight. The supernatant was filtered with a $0.22 \mu \mathrm{m}$ filter. An aliquot of $100 \mu \mathrm{L}$ of filtered supernatant was drawn and diluted to $100 \mathrm{~mL}$ with water. By measuring the peak area of the diluted solution, it was possible to determine the solubility of L-arabinose at a certain temperature (Table 1).

\section{Solubility of L-arabinose in impure water system}

Potassium and calcium are ubiquitous inorganic ions. Determination of the L-arabinose solubility in the presence of these ions, therefore, is very instructive for L-arabinose production. The measurement of L-arabinose solubility in the presence of impurity was similar to that in pure water system, but 1.0-4.0\% impurity was added. Figures $3 \mathrm{a}$ and $\mathrm{b}$ showed the L-arabinose solubility in the presence of Potassium chloride and Calcium chloride, respectively.

\subsection{Seeded Metastable Zone Width in pure water system}

All experiments were conducted using a simple experimental setup, as shown in Figure 4. Fifty grams of L-arabinose and a certain amount of water were first transferred to the crystallizer loaded with a thermocouple (K-type, Omega, USA) connecting to a USB TC-08 in-line temperature logger (Pico technology, England). After fully dissolved, the solution was cooled to room temperature. In the process of cooling, a seed crystal (about $2 \mathrm{~mm} \times 2 \mathrm{~mm} \times 10 \mathrm{~mm}$ ) was added to the crystallizer when the solution reached the saturation temperature. The seed crystal was suspended by a fine nylon thread vertically into the crystallizer avoiding contact with the crystallizer wall, thermocouple wire, and the magnetic stirrer preventing collisions and breakage of the crystal.

The inflection point of the temperature curve is defined as $T_{m}$, as illustrated in Figure 5. The nucleation point was easily detected as the appearance of the inflection point of the solution temperature (Figure 5b). The temperature rise was about $0.5-2{ }^{\circ} \mathrm{C}$; $T_{m}$ of $51-73 \% \mathrm{~L}$-arabinose solution is shown in Table 2. The crystallizer mentioned above was a $50 \mathrm{~mL}$ round-bottom flask with a rubber stopper. The stirring rate was $50 \mathrm{rpm}$.

Table 1. Average peak area and solubility of L-arabinose.

\begin{tabular}{cccccc}
\hline $\begin{array}{c}\text { Temperature } \\
{ }^{\circ} \mathrm{C}\end{array}$ & $\begin{array}{c}\text { Peak } \\
\mathrm{nC}^{*} \mathrm{~min}\end{array}$ & $\begin{array}{c}\text { Solubility } \\
\mathrm{g} / 100 \mathrm{~g} \\
\text { water }\end{array}$ & $\begin{array}{c}\text { Temperature } \\
{ }^{\circ} \mathrm{C}\end{array}$ & $\begin{array}{c}\text { Peak } \\
\mathrm{nC}^{*} \mathrm{~min}\end{array}$ & $\begin{array}{c}\text { Solubility } \\
\mathrm{g} / 100 \mathrm{~g} \\
\text { water }\end{array}$ \\
\hline 20 & 347.4 & 75.44 & 50 & 444.3 & 122.22 \\
25 & 367.3 & 83.36 & 53 & 456.4 & 129.88 \\
28 & 376.5 & 87.27 & 54 & 461.3 & 133.10 \\
30 & 379.7 & 88.68 & 55 & 462.9 & 134.19 \\
32 & 383.7 & 90.48 & 57 & 466.9 & 136.97 \\
34 & 389.4 & 93.05 & 60 & 471.8 & 140.38 \\
36 & 395.9 & 96.08 & 63 & 479.9 & 146.31 \\
38 & 399.9 & 98.02 & 65 & 484.7 & 150.01 \\
45 & 428.2 & 112.77 & 68 & 499.3 & 161.78 \\
\hline
\end{tabular}




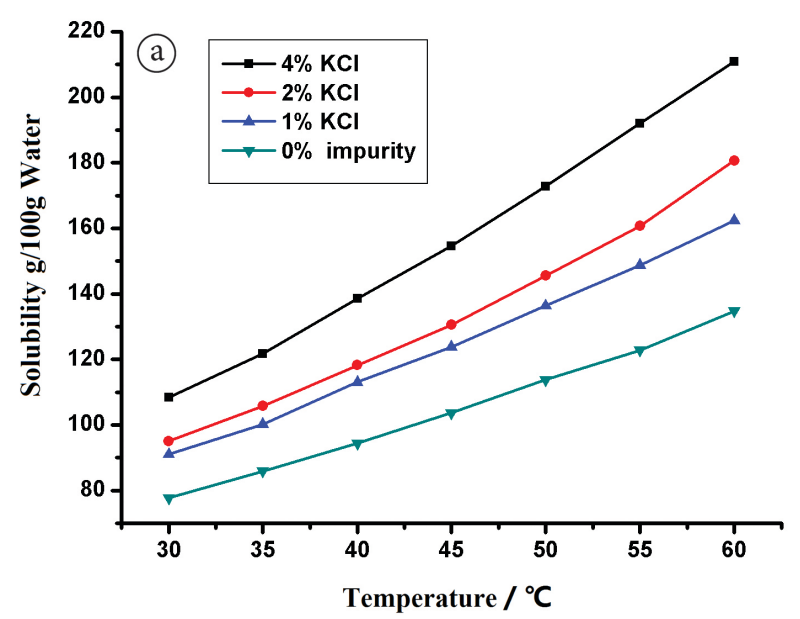

Figure 3. Effect of impurity on the solubility of L-arabinose.

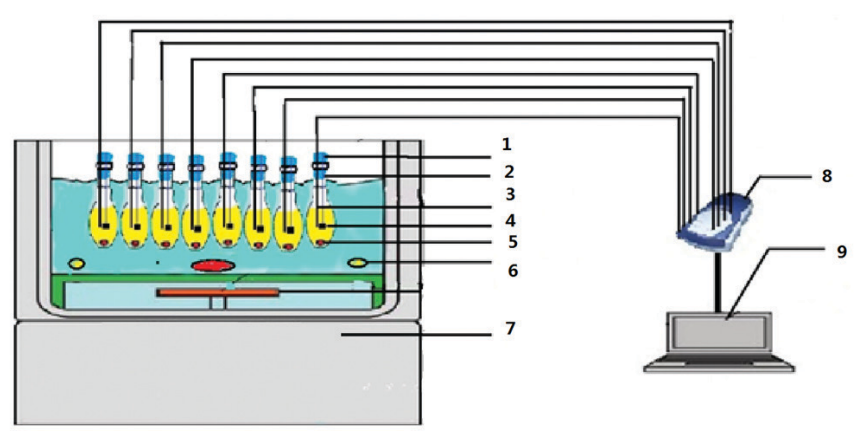

Figure 4. Schematic of experimental setup: (1) rubble stopper; (2) crystallizer; (3) Thermocouple; (4) Crystal Seed; (5) Magnetic rotor; (6) heater (7) Water bath; (8) Data logging module; and (9) Computer.

\subsection{Metastable Zone Width in the presence of impurity}

To evaluate the effect of impurity on the MSZW of L-arabinose, $2.0 \%$ and $4.0 \%$ of impurity were added to the L-arabinose solution before complete dissolution of the L-arabinose; results are shown in Figure 6.

\section{Results and discussion}

\subsection{Solubility}

Solubility of L-arabinose in pure water system

The solid-liquid equilibrium of a L-arabinose-water system over the temperature range from $20^{\circ} \mathrm{C}$ to $68^{\circ} \mathrm{C}$ was determined (Table 1). The relationship between solubility and temperature can be satisfactorily described by Equation 2 .

$W=55.492+0.7637 T+0.0113 T^{2}\left(R^{2}=0.995\right)$

Where $W$ is saturated concentration (gram L-arabinose per 100 gram water), and $T$ is temperature in Celsius.

\section{Solubility of L-arabinose in Potassium chloride-water system}

To analyze the effect of Potassium chloride on the solubility of L-arabinose in aqueous solution, 1.0-4.0\% Potassium chloride was added. Results show that $\mathrm{L}$-arabinose is more soluble in the

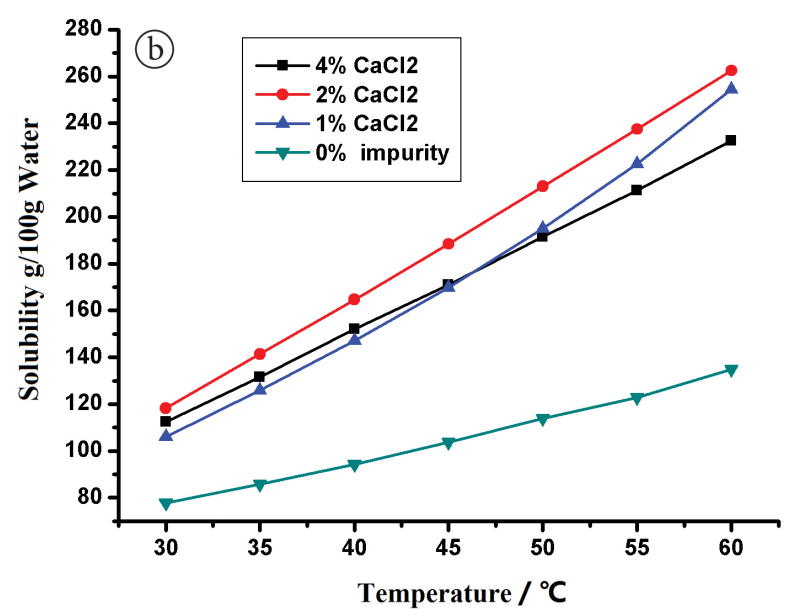

Potassium chloride-water system (Figure 3a). The solubility increment increases with the increase in concentration from $1.0 \%$ to $4.0 \%$. For example, at $35{ }^{\circ} \mathrm{C}$, the solubility increments in $1 \%, 2 \%$, and $4 \%$ (Potassium chloride) were $17.3 \%, 22.2 \%$, and $24.5 \%$, respectively. The solubility increment in the Potassium chloride-water system increases with temperature rise; take $4.0 \%$ for example, the increments were $9.0 \%, 11.4 \%, 13.4 \%$, $15.1 \%, 16.5 \%, 17.7 \%$, and $18.7 \%$, respectively, at $30-60^{\circ} \mathrm{C}\left(5^{\circ} \mathrm{C}\right.$ increments).

This could be explained by the melassigenic effect and salting-in effect. Some researches (Day-Lewis, 1993; Quentin, 1957) stated that the presence of salt can increase the sucrose solubility in molasses, and the relative solubility increment obtained was: potassium $>$ sodium $>$ calcium. Sahadeo (1998), however, stated that the melassigenic effect of salt was: sodium $>$ calcium $>$ magnesium $>$ potassium. No matter which cation has the greatest melassigenic effect, it cannot be denied that potassium ion has melassigenic effect, which increases the solubility of L-arabinose.

It is known that Potassium chloride has salting-in effect at low concentration. Ferreira et al. (2007) stated that the solubility of five amino acids increased with the increase in potassium chloride concentration from $0 \mathrm{M}$ to $1 \mathrm{M}(7.45 \%)$. Accordingly, in the present study, it was found that the solubility of L-arabinose in the potassium chloride-water system is higher than that in the pure water system at all temperatures tested, and the increment was: $4.0 \%$ Potassium chloride $>2.0 \%$ Potassium chloride $>1.0 \%$ Potassium chloride.

\section{Solubility of L-arabinose in calcium chloride-water system}

Figure $3 \mathrm{~b}$ demonstrates the influence of calcium chloride on the solubility of L-arabinose in aqueous solution. Similar to the effect of potassium chloride, the solubility increases with the rise in temperature from $30-60{ }^{\circ} \mathrm{C}$, and the solubility increment increases with temperature rise. For example, the solubility increments in the $1.0 \%$ calcium chloride-water system is $22.3 \%$, $29.6 \%, 38.2 \%, 47.6 \%, 57.7 \%, 68.1 \%$, and $78.6 \%$ at $30-60{ }^{\circ} \mathrm{C}\left(5^{\circ} \mathrm{C}\right.$ increments), respectively; it is $33.1 \%, 46.6 \%, 57.7 \%, 66.8 \%, 74.2 \%$, 

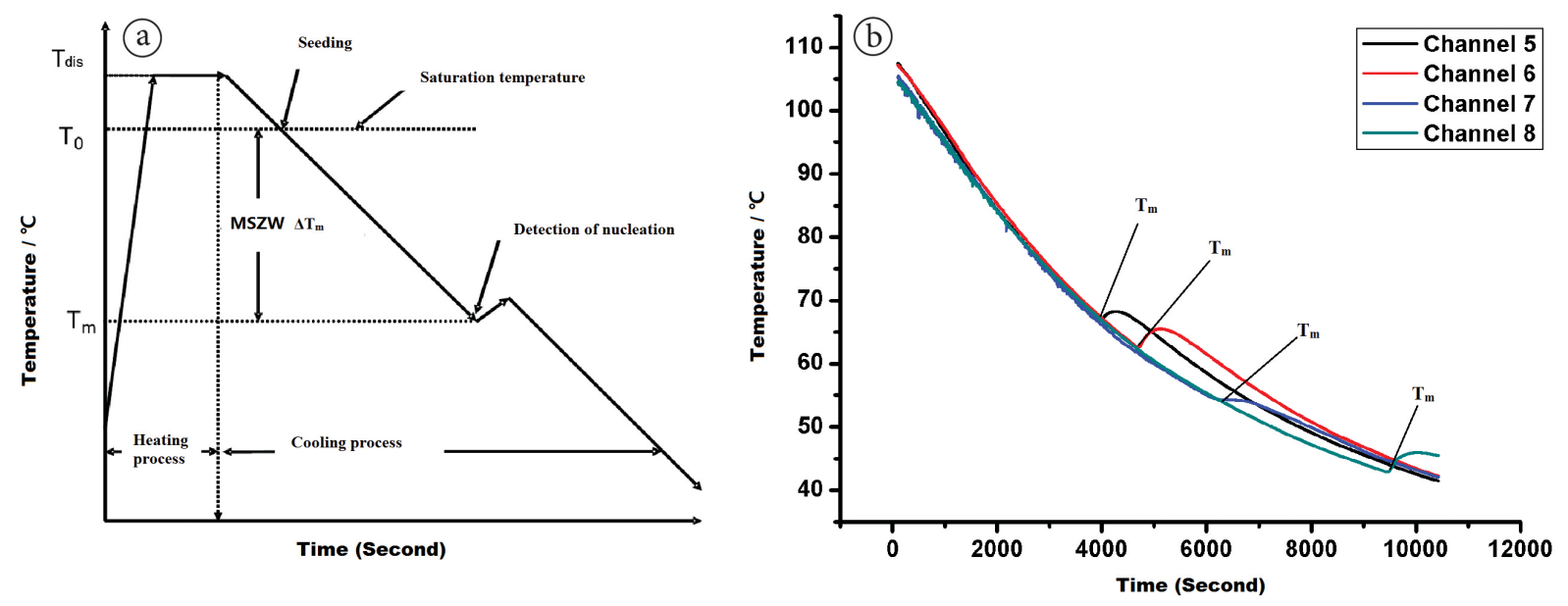

Figure 5. Definition of MSZW and detection of $T_{m}: 5 \mathrm{a}$ Schematic of MSZW definition and $5 \mathrm{~b} T_{m}$ detection in a typical temperature profile of cooling process.
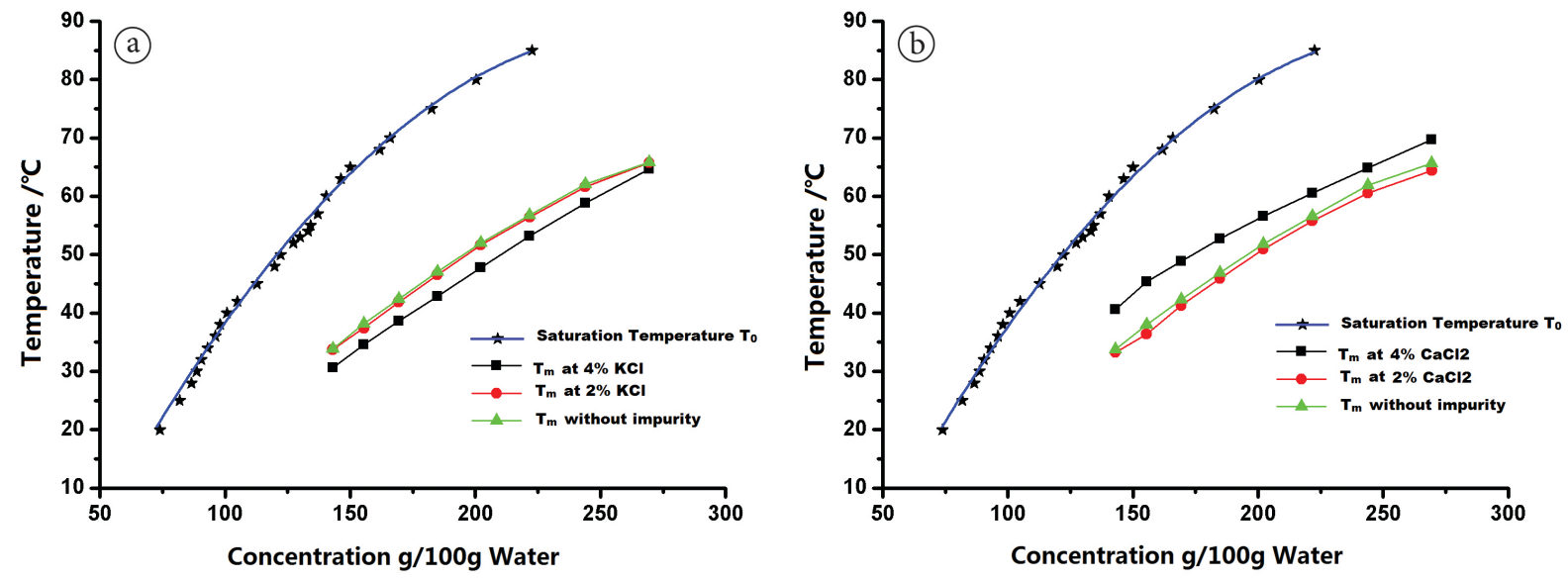

Figure 6. Effect of impurity on the MSZW of L-arabinose.

Table 2. Seeded metastable zone width of L-arabinose in pure water system.

\begin{tabular}{cccccc}
\hline concentration & Solubility & $\mathrm{To}^{*}$ & $\mathrm{~T}_{\mathrm{m} 1}$ & $\mathrm{~T}_{\mathrm{m} 2}$ & $\Delta \mathrm{T}$ (average) \\
\hline $51 \%$ & 104.08 & 40.20 & - & - & - \\
$53 \%$ & 112.76 & 45.36 & 13.25 & 12.03 & 32.72 \\
$55 \%$ & 122.22 & 50.52 & 21.98 & 23.42 & 27.82 \\
$57 \%$ & 132.56 & 55.68 & 29.49 & 33.16 & 24.36 \\
$59 \%$ & 143.90 & 60.84 & 38.21 & 35.48 & 24.99 \\
$61 \%$ & 156.41 & 66.00 & 41.75 & 39.09 & 25.58 \\
$63 \%$ & 170.27 & 71.16 & 45.73 & 44.60 & 25.99 \\
$65 \%$ & 185.71 & 76.32 & 51.63 & 51.94 & 25.54 \\
$67 \%$ & 203.03 & 81.48 & 54.37 & 53.43 & 27.58 \\
$69 \%$ & 222.58 & 86.64 & 60.65 & 57.65 & 27.49 \\
$71 \%$ & 244.83 & 91.80 & 65.66 & 63.84 & 27.05 \\
$73 \%$ & 270.37 & 96.96 & 69.17 & 66.41 & 29.17 \\
\hline
\end{tabular}

$80.2 \%$ and $84.9 \%$ in a $2.0 \%$ calcium chloride-water system. It is observed that solubility increment in the calcium chloride-water system is higher than that of the Potassium chloride-water system under the same conditions. Take samples at $40{ }^{\circ} \mathrm{C}$ for example, the solubility increments were $38.2 \%, 57.7 \%$, and $48.5 \%$ in $1.0 \%, 2.0 \%, 4.0 \%$ calcium chloride-water system, while in the potassium chloride-water system it were $7.7 \%, 11.5 \%$, and $13.4 \%$.

In addition to the melassigenic effect and salting-in effect, another possible factor is that $\mathrm{L}$-arabinose can react with calcium chloride to form different types of compounds (Dale, 1934; Austin \& Walsh, 1934), such as $\alpha$-L-arabinose calcium chloride $4 \mathrm{H}_{2} \mathrm{O},(\beta \text {-L-arabinose })_{2} \cdot$ calcium chloride $2 \mathrm{H}_{2} \mathrm{O}$, and $(\beta \text {-L-arabinose })_{2} \cdot$ calcium chloride $\cdot \mathrm{H}_{2} \mathrm{O}$. These compounds might change the equilibrium of L-arabinose-water system, which affects the solubility of L-arabinose. Among the systems 
evaluated, $2.0 \%$ calcium chloride had the greatest solubility increment, which is in accordance with Mendonca's study, who found that low concentration of salt had salting-in effect, while high concentration had more salting-out effect (Mendonça et al., 2003). Accordingly, in the present study, it was found that the solubility of L-arabinose in the calcium chloride-water system increased compared with that of the pure water system at $30-60^{\circ} \mathrm{C}$ and that the solubility increment in the calcium chloride-water system is higher than that of the potassium chloride-water system under the same conditions.

\subsection{MSZW detection}

\section{Detection of MSZW in pure water system}

Detection of seeded MSZW was conducted using a simple experimental setup, as shown in Figure 4. The temperature of nucleation point is defined as $T_{m}$. The extent of supercooling is defined as MSZW, which is equal to the value between the temperature of saturation $\left(T_{0}\right)$ and nucleation point $\left(T_{m}\right)$ (Figure 5). A typical temperature profile was illustrated in Figure 5b. The inflection point of the temperature profile is detected and termed as $T_{m}$, which represents the temperature of nucleation point.

Table 2 shows $T_{m}$ at the concentrations of 51-73\%. Ice was added to the water bath because the $T_{m}$ measured was below room temperature at $51.0-55.0 \%$. The relationship between supersaturation and temperature can be satisfactorily described by the following exponential Equation 3:

$W s=93.434+0.4105 T+0.0337 T^{2}$

Where $W_{s}$ is supersaturation ( $\mathrm{g} / 100 \mathrm{~g}$ water) and $T$ is temperature.

As can be seen in Table 2, the MSZW $\left(\Delta T_{m}\right)$ is not constant but a spread from $24.36-32.72^{\circ} \mathrm{C}($ Mean \pm Std. Deviation $=27.11 \pm 2.34)$, which might be explained by the following reasons. Firstly, MSZW is a function of the induction time of nucleation $\left(t_{\text {ind }}\right)$ and cooling rate (Zhang et al., 2012; Herden et al., 2001; Kobari et al., 2010; Kim \& Mersmann, 2001; Sangwal, 2011). It has been pointed out that $\log \left(\Delta T_{m}\right)$ increased linearly with an increase in $\log$ $\mathrm{R}$ (cooling rate). Therefore, the log $\mathrm{R}$ was not constant, but it changed which resulting in the deflection of MSZW. Secondly, the size and number of the seed crystals influences the MSZW of secondary nucleation (Herden et al., 2001). Thus, a large crystal was suspended in the solution. However, the size of the seed crystal is not identical, which might lead to the deflection of MSZW. Thirdly, the volume of the crystallizer and the stirring rate also had great influence on MSZW. It has been stated that the MSZW is not a reproducible point at small volumes but a spread which increases roughly inversely proportional to the volume (Kadam et al., 2012). In addition, MSZW is influenced by the detection method and sensitivity. To reach the detectable $T_{m}$, the dissipated latent heat has to overcome the heat emission from solution to environment, which means that there exists a time lag between nucleation point and detection point (Kubota et al., 2013).

\section{Detection of MSZW in impure water system}

In many instances, small amounts of impurities have dramatic effects on crystal growth, morphology, and nucleation. Therefore, the influence of Potassium chloride and calcium chloride on the seeded MSZW of L-arabinose was investigated. The seeded MSZW of L-arabinose in the Potassium chloride-water system and calcium chloride-water system are shown in Figures $6 a$ and $b$, respectively.

The $T_{m}$ in the $4.0 \%$ Potassium chloride-water system is lower than that in the $2.0 \%$ Potassium chloride-water system, which is slightly lower than that of the pure water system. In other words, the MSZW increases in the potassium chloride-water system, and the higher the potassium chloride concentration, the larger the MSZW. A possible reason is that the solubility of $\mathrm{L}$-arabinose increases due to the addition of potassium chloride, which would reduce the effective supersaturation. Another reason is that impurities can change the nucleation rate by affecting both the kinetic factor and interfacial energy (Sangwal, 2009; Herden et al., 2001). The findings obtained in the present study are similar to those in Dhanaraj's research, who found that adding $\mathrm{K}^{+}$ion increased the MSZW of KDP thus making the solution more stable and inhibiting spontaneous nucleation (Dhanaraj et al., 2008).

The $T_{m}$ is sensitive to calcium chloride concentration. The relationship of $T_{m}$ in the pure water system and calcium chloride-water system is: $T_{m}(2.0 \%$ calcium chloride $)>T_{m}$ (pure water $)>T_{m}(4.0 \%$ calcium chloride); this is consistent with other studies that reported that there are solute-solvent systems in which the MSZW either first increase then decrease or first decrease then increase with the increasing of impurity (Haja Hameed et al., 2007). This could be explained by the change in saturation temperature and nucleation rate. It has been proved that addition of $\mathrm{Ca}^{2+}$ changes the saturation temperature of borax decahydrate and boric acid and the effect is concentration dependent (Gürbüz \& Özdemir, 2003; Sayan \& Ulrich, 2001). In the present study, it was proved that the solubility increment in the $2.0 \%$ calcium chloride-water system was larger than that in the $4.0 \%$ calcium chloride-water system. Thus, the addition of calcium chloride would change the effective supersaturation, which leads to the change of MSZW. Calcium chloride might also have an influence on MSZW by acting as a nucleation enhancer or as a nucleation inhibitor, such as nickel (Mielniczek \& Sangwal, 2004). By acting as a nucleation enhancer, it would decrease the MSZW of the solute, whereas as a nucleation inhibitor, it would increase the MSZW of the solute.

(Sangwal, 2009). However, the influence of calcium chloride on the seeded MSZW of L-arabinose by modifying the nucleation rate has not been proved yet. In this study, it was found that the seeded MSZW of L-arabinose decreases in the $2.0 \%$ calcium chloride-water system and increases in the $4.0 \%$ calcium chloride-water system.

\section{Conclusion}

As a new functional sugar, L-arabinose can be used in many fields such as food and medicine industries and others. Detection of the solubility and seeded metastable zone width 
of L-arabinose in aqueous solution can be of great importance in the production and use of L-arabinose.

In this study, solubility and seeded MSZW of L-arabinose with and without impurity was determined. The following conclusions can be drawn:

(1) The solid-liquid equilibrium of a L-arabinose-water system from $20-68^{\circ} \mathrm{C}$ is determined, which can be described by $W=55.492+0.7637 \mathrm{~T}+0.0113 \mathrm{~T}^{2}\left(R^{2}=0.995\right)$.

(2) The solubility of L-arabinose in the potassium chloride-water system is higher than that of the pure water system, and the solubility increment at $4.0 \%$ potassium chloride $>2.0 \%$ potassium chloride $>1.0 \%$ Potassium chloride. Solubility increment in the calcium chloride-water system is higher than that of the potassium chloride-water system under the same conditions. Among all systems evaluated, the $2.0 \%$ calcium chloride system had the greatest solubility increment, while the $1.0 \%$ and $4.0 \%$ systems had almost the same solubility increment.

(3) Calorimetric method is used to detect the temperature of nucleation. The MSZW $\left(\Delta T_{m}\right)$ is not constant but a spread (Mean \pm Std. Deviation $=27.11 \pm 2.34$ ) in the pure water system. The MSZW increased in the presence of potassium chloride, and the MSZW increment was $4.0 \%$ potassium chloride $>2.0 \%$ potassium chloride. However, The MSZW of L-arabinose increased in the $4.0 \%$ calcium chloride-water system and decreased in the $2.0 \%$ calcium chloride-water system.

\section{Acknowledgements}

This study was supported by the Ministry of Science and Technology through the Agriculture Science and Technology Achievements Transformation Fund (No. 2013GB23600669) and by The Science and Technology Planning Project of Guangzhou Municiplity, China (No. 2011Y2-00012).

\section{References}

Andrade, E. C. B., Barros, A. M., \& Takase, I. (2003). Evaluation of the solubility of Copper and Zinc in a salty, watery vegetable soup. Ciência e Tecnologia de Alimentos, 23(3), 386-388. http://dx.doi. org/10.1590/S0101-20612003000300016.

Austin, W. C., \& Walsh, J. P. (1934). A.; Walsh, J. P. A new crystalline compound of a-l-Arabinose with calcium chloride and water. Journal of the American Chemical Society, 56(4), 934-935. http:// dx.doi.org/10.1021/ja01319a051.

Barrett, P., \& Glennon, B. (2002). Characterizing the metastable zone width and solubility curve using Lasentec FBRM and PVM. Chemical Engineering Research \& Design, 80(7), 799-805. http:// dx.doi.org/10.1205/026387602320776876.

Becker, J., \& Boles, E. (2003). A modified Saccharomyces cerevisiae strain that consumes L-Arabinose and produces ethanol. Applied and Environmental Microbiology, 69(7), 4144-4150. http://dx.doi. org/10.1128/AEM.69.7.4144-4150.2003. PMid:12839792

Black, S., Dang, L., Liu, C., \& Wei, H. (2013). On the measurement of solubility. Organic Process Research \& Development, 17(3), 486-492. http://dx.doi.org/10.1021/op300336n.
Choung, B. S., Kim, I. H., Jeon, B. J., Lee, S., Kim, S. H., Kim, S. W., Lee, S. O., Lee, S. T., \& Kim, D. G. (2012). Long-term treatment efficacy and safety of clevudine therapy in naïve patients with chronic hepatitis B. Gut and liver, 6(4), 486-492. http://dx.doi.org/10.5009/ gnl.2012.6.4.486. PMid:23170155

Dale, J. K. (1934). Crystalline compounds of d-Xylose and of l-Arabinose with calcium chloride. Journal of the American Chemical Society, 56(4), 932-934. http://dx.doi.org/10.1021/ja01319a050.

Day-Lewis, C. (1993). The effect of individual ash constituents on molasses exhaustion: A literature survey (Sugar Milling Research Institute Technical Report, No. 1656, pp. 10-12). Durban: Sugar Milling Research Institute.

Dhanaraj, P. V., Mahadevan, C. K., Bhagavannarayana, G., Ramasamy, P., \& Rajesh, N. P. (2008). Growth and characterization of KDP crystals with potassium carbonate as additive. Journal of Crystal Growth, 310(24), 5341-5346. http://dx.doi.org/10.1016/j.jcrysgro.2008.09.019.

Elder, D., \& Holm, R. (2013). Aqueous solubility: simple predictive methods (in silico, in vitro and bio-relevant approaches). International Journal of Pharmaceutics, 453(1), 3-11. http://dx.doi.org/10.1016/j. ijpharm.2012.10.041. PMid:23124107

El-Farargy, A. F., \& Ghonium, A. A. (2008). Synthesis of some new C-nucleosides from L-arabinose and D-glucose. ARKIVOC, 2008(13), 278-285. http://dx.doi.org/10.3998/ark.5550190.0009.d30.

Ferreira, L. I. S. A., Macedo, E. E. N. A., \& Pinho, S. A. O. P. (2007). $\mathrm{KCl}$ effect on the solubility of five different amino acids in water. Fluid Phase Equilibria, 255(2), 131-137. http://dx.doi.org/10.1016/j. fluid.2007.04.004.

Fu-Yu, B., Ji-Cheng, D., \& Zhao-Wei, Z. (2010). Application of L-arabinose in processing chiffon cake. Food Engineering, 2010(1), 48-50.

Gürbüz, H., \& Özdemir, B. (2003). Experimental determination of the metastable zone width of borax decahydrate by ultrasonic velocity measurement. Journal of Crystal Growth, 252(1-3), 343-349. http:// dx.doi.org/10.1016/S0022-0248(02)02519-8.

Haja Hameed, A. S., Rohani, S., Yu, W. C., Tai, C. Y., \& Lan, C. W. (2007). Growth and characterization of a new chelating agent added 4-dimethylamino- N-methyl-4-stilbazolium tosylate (DAST) single crystals. Materials Chemistry and Physics, 102(1), 60-66. http:// dx.doi.org/10.1016/j.matchemphys.2006.11.004.

Herden, A., Mayer, C., Kuch, S., \& Lacmann, R. (2001). About the metastable zone width of primary and secondary nucleation. Chemical Engineering \& Technology, 24(12), 1248-1254. http://dx.doi.org/10.1002/15214125(200112)24:12<1248::AID-CEAT1248>3.0.CO;2-W.

Jeon, Y. J., Park, M. B., \& Kim, I. H. (2010). L-Ribose from L-arabinose by epimerization and its purification by 3 -zone simulated moving bed chromatography. Bioprocess and Biosystems Engineering, 33(1), 87-95. http://dx.doi.org/10.1007/s00449-009-0375-0. PMid:19714365

Jeong, J. H., Kim, K., Lim, D., Jeong, K., Hong, Y., Nguyen, V. H., Kim, T. H., Ryu, S., Lim, J. A., Kim, J. I., Kim, G. J., Kim, S. C., Min, J. J., \& Choy, H. E. (2014). Anti-tumoral effect of the mitochondrial target domain of Noxa delivered by an engineered Salmonella typhimurium. PLoS ONE, 9(1), e80050. http://dx.doi.org/10.1371/ journal.pone.0080050. PMid:24416126

Jia, J. D., Hou, J. L., Yin, Y. K., Tan, D. M., Xu, D., Niu, J. Q., Zhou, X. Q., Wang, Y. M., Zhu, L. M., Chen, C. W., He, Y. W., Ren, H., Wan, M. B., Wu, S. M., Wang, Q. H., Wei, L., Bao, W., Dong, Y., \& Trylesinski, A. (2014). Two-year results of a randomized, phase III comparative trial of telbivudine versus lamivudine in Chinese patients. Hepatology International, 8(1), 72-82.

Kadam, S. S., Kulkarni, S. A., Coloma Ribera, R., Stankiewicz, A. I., ter Horst, J. H., \& Kramer, H. J. M. (2012). A new view on the metastable 
zone width during cooling crystallization. Chemical Engineering Science, 72, 10-19. http://dx.doi.org/10.1016/j.ces.2012.01.002.

Kaluzhny, D. N., Tatarskiy, V. V. Jr, Dezhenkova, L. G., Plikhtyak, I. L., Miniker, T. D., Shchyolkina, A. K., Strel'tsov, S. A., Chilov, G. G., Novikov, F. N., Kubasova, I. Y., Smirnova, Z. S., Mel'nik, S. Y., Livshits, M. A., Borisova, O. F., \& Shtil, A. A. (2009). Novel antitumor $\mathrm{L}$-arabinose derivative of indolocarbazole with high affinity to DNA. ChemMedChem, 4(10), 1641-1648. http://dx.doi.org/10.1002/ cmdc.200900227. PMid:19672918

Kim, K., \& Mersmann, A. (2001). Estimation of metastable zone width in different nucleation processes. Chemical Engineering Science, 56(7), 2315-2324. http://dx.doi.org/10.1016/S0009-2509(00)00450-4.

Kobari, M., Kubota, N., \& Hirasawa, I. (2010). Simulation of metastable zone width and induction time for a seeded aqueous solution of potassium sulfate. Journal of Crystal Growth, 312(19), 2734-2739. http://dx.doi.org/10.1016/j.jcrysgro.2010.05.042.

Krog-Mikkelsen, I., Hels, O., Tetens, I., Holst, J. J., Andersen, J. R., \& Bukhave, K. (2011). The effects of L-arabinose on intestinal sucrase activity: dose-response studies in vitro and in humans. The American Journal of Clinical Nutrition, 94(2), 472-478. http://dx.doi. org/10.3945/ajcn.111.014225. PMid:21677059

Kubota, N., Kobari, M., \& Hirasawa, I. (2013). Analytical and numerical study of detector sensitivity and resolution effects on metastable zone width. CrystEngComm, 15(11), 2091-2098. http://dx.doi. org/10.1039/c2ce26968f.

Li, X., Wang, Y., Han, D., Zhang, W., Zhang, Z., Ye, X., Tian, L., Dong, Y., Zhu, Q., \& Chen, Y. (2014). Correlation of hepatitis B surface antigen level with response to telbivudine in naive patients with chronic hepatitis B. Hepatology Research: the official journal of the Japan Society of Hepatology, 44(2), 187-193. http://dx.doi.org/10.1111/ hepr.12105. PMid:23607803

Liu, X., Zhu, D., Sun, L., Gao, Y., \& Wang, C. (2013). [Effect of L-arabinose on the postprandial blood glucose and body weight]. Journal of Hygiene Research, 42(2), 295-297. PMid:23654110.

Loessner, H., Endmann, A., Leschner, S., Westphal, K., Rohde, M., Miloud, T., Hämmerling, G., Neuhaus, K., \& Weiss, S. (2007). Remote control of tumour-targeted Salmonella enterica serovar Typhimurium by the use of L-arabinose as inducer of bacterial gene expression in vivo. Cellular Microbiology, 9(6), 1529-1537. http:// dx.doi.org/10.1111/j.1462-5822.2007.00890.x. PMid:17298393

Mendonça, Â. F. S. S., Pereira, S. N. R., \& Lampreia, I. M. S. (2003). Solubility of Triethylamine in Calcium Chloride Aqueous Solutions from 20 to 35 C. Journal of Solution Chemistry, 32(12), 1033-1044. http://dx.doi.org/10.1023/B:JOSL.0000023919.48142.ee.

Mielniczek-Brzóska, E., \& Sangwal, K. (2004). Growth kinetics of ammonium oxalate monohydrate single crystals from aqueous solutions containing Co (II) and Ni (II) impurities. Crystal Research and Technology, 39(11), 993-1005. http://dx.doi.org/10.1002/ crat.200410284.

Mikhalev, O. I., Kaplan, A. M., \& Trofimov, V. I. (1985). On the latent heat of crystallization of water in cooled solutions. Chemical Physics Letters, 121(6), 547-550. http://dx.doi.org/10.1016/00092614(85)87138-4.

Po, Q., Ji-Cheng, D., \& Fu-Lai, B. (2011). Research progress and application status of L-arabinose. Food Research and Development, 1, 160-163.

Quentin, G. (1957). Der Einfluss der Kationen auf die Saccharoselöslichkeit in Melassen und die Möglichkeiten einer technologischen Auswertung der unterschiedlichen Loslichkeitsbeeinflussung. Zucker, 10, 408.

Rabesiaka, M., Porte, C., Bonnin-Paris, J., \& Havet, J.-L., and the Rabesiaka (2011). An automatic method for the determination of saturationcurve and matastable zone width of lysine monohydrochloride. Journal of Crystal Growth, 332(1), 75-80. http://dx.doi.org/10.1016/j. jcrysgro.2011.07.016.

Sahadeo, P. (1998). The Effect of some Impurities on Molasses Exhaustion. In Proceedings of the Annual Congress South African Sugar Technologists' Association (Vol. 72, pp. 285-289), Durban, South African.

Salomatov, V. V. (1966). Growth rate of a crystal dissipating latent heat of crystallization by radiation. Soviet Physics Journal, 9(1), 38-39. http://dx.doi.org/10.1007/BF00818488.

Sangwal, K. (2009). Effect of impurities on the metastable zone width of solute--solvent systems. Journal of Crystal Growth, 311(16), 40504061. http://dx.doi.org/10.1016/j.jcrysgro.2009.06.045.

Sangwal, K. (2011). Recent developments in understanding of the metastable zone width of different solute-solvent systems. Journal of Crystal Growth, 318(1), 103-109. http://dx.doi.org/10.1016/j. jcrysgro.2010.11.078.

Sayan, P., \& Ulrich, J. (2001). Effect of various impurities on the metastable zone width of boric acid. Crystal Research and Technology, 36(4-5), 411-417. http://dx.doi.org/10.1002/1521-4079(200106)36:4/5<411::AIDCRAT411>3.0.CO;2-L.

Seri, K., Sanai, K., Matsuo, N., Kawakubo, K., Xue, C., \& Inoue, S. (1996). $\mathrm{L}$-arabinose selectively inhibits intestinal sucrase in an uncompetitive manner and suppresses glycemic response after sucrose ingestion in animals. Metabolism: Clinical and Experimental, 45(11), 1368-1374. http://dx.doi.org/10.1016/S0026-0495(96)90117-1. PMid:8931641

Shibanuma, K., Degawa, Y., \& Houda, K. (2011). Determination of the transient period of the EIS complex and investigation of the suppression of blood glucose levels by L-arabinose in healthy adults. European Journal of Nutrition, 50(6), 447-453. http://dx.doi. org/10.1007/s00394-010-0154-3. PMid:21165628

Shiroishi, A., Yoshida, M., Yamane, T., \& Miyashita, H. (1999). Flow and temperature fields under natural convection due to crystal growth in supersaturated solution. Journal of Chemical Engineering of Japan, 32(4), 389-394. http://dx.doi.org/10.1252/jcej.32.389.

Sun, Y., Song, X., Wang, J., Luo, Y., \& Yu, J. (2010). Determination of seeded supersolubility of lithium carbonate using FBRM. Journal of Crystal Growth, 312(2), 294-300. http://dx.doi.org/10.1016/j. jcrysgro.2009.10.036.

Três, M. V., Francheschi, E., Borges, G. R., Dariva, C., Corazza, F. C., Oliveira, J. V., \& Corazza, M. L. (2007). Influência da temperatura na solubilidade de beta-caroteno em solventes orgânicos à pressão ambiente. Ciência e Tecnologia de Alimentos, 27(4), 737-743. http:// dx.doi.org/10.1590/S0101-20612007000400011.

Wu, S., Feng, F., Zhou, L., \& Gong, J. (2012). Experimental determination of the solid--liquid equilibrium, metastable zone, and nucleation parameters of the flunixin meglumine--ethanol system. Journal of Crystal Growth, 354(1), 164-168. http://dx.doi.org/10.1016/j. jcrysgro.2012.05.031.

Yamauchi, S., \& Kinoshita, Y. (2001). Synthesis of cis-lactone lignan, cis(2S,3R)-parabenzlactone, from L-arabinose. Bioscience, Biotechnology, and Biochemistry, 65(7), 1669-1672. http://dx.doi.org/10.1271/ bbb.65.1669. PMid:11515556

Yoon, H. S., Kim, C. H., Kim, T. J., Keum, I., \& Han, N. S. (2003). Novel functional sugar l-arabinose: its functionality, uses and production method. Korean Journal of Food Science and Technology, 35(5), 757-763.

Zhang, X., Wang, X., Hao, L., Yang, X., Dang, L., \& Wei, H. (2012). Solubility and metastable zone width of DL-tartaric acid in aqueous solution. Crystal Research and Technology, 47(11), 1153-1163. http:// dx.doi.org/10.1002/crat.201200166. 